\title{
Quality of life in pre- and postmenopausal patients with early breast cancer: a comprehensive analysis from the prospective MaLife project
}

\author{
Norbert Marschner ${ }^{1}\left(\mathbb{D} \cdot\right.$ Tanja Trarbach $^{2} \cdot$ Jacqueline Rauh $^{3} \cdot$ Dirk Meyer $^{4} \cdot$ Sigrun Müller-Hagen $^{5} \cdot$ Johanna Harde $^{6}$. \\ Stephanie Dille ${ }^{7}$ Lisa Kruggel ${ }^{8} \cdot$ Martina Jänicke $^{8} \cdot$ The TMK-Group (Tumour Registry Breast Cancer) $^{2}$
}

Received: 5 November 2018 / Accepted: 6 March 2019 / Published online: 13 March 2019

(c) The Author(s) 2019

\begin{abstract}
Purpose Quality of life (QoL) plays an important role in recovery-especially after an incisive diagnosis such as breast cancer. Here, we present a comprehensive assessment of QoL for pre- and postmenopausal patients, starting from initial systemic treatment of early breast cancer until 3 years later, in patients from a so-called "real-world" setting.

Methods 251 premenopausal and 478 postmenopausal patients with early breast cancer have been recruited into the longitudinal MaLife project within the prospective, multicentre, German Tumour Registry Breast Cancer between 2011 and 2015. The questionnaires FACT-G, FACT-Taxane, FACT-ES, EORTC QLQ-BR23, BFI and HADS were filled in at start of treatment (T0), 6, 12, 24 and 36 months later. The proportion of patients with clinically meaningful changes at 36 months was determined.

Results This first interim analysis shows that the FACT-G global QoL improved over time regardless of the menopausal status. However, clinically meaningful decrease of social/family well-being (48-51\%), arm symptoms (44-49\%) and symptoms of neurotoxicity (55-56\%) was frequently reported 3 years after start of treatment. Many premenopausal patients also reported a clinically meaningful worsening of endocrine symptoms (64\%), emotional well-being (36\%) and fatigue intensity (37\%). Additionally, 3 years after start of treatment, $15 \%$ of the patients were classified as doubtful cases and $18 \%$ as definite cases of anxiety.

Conclusions Despite improvements in global QoL, breast cancer survivors report worsened ailments 3 years after start of therapy. Follow-up care should distinguish between premenopausal patients needing special attention for emotional/menopausal issues, and postmenopausal patients needing particular care regarding physical concerns.
\end{abstract}

Keywords Breast neoplasms · Registries · Cohort studies · Quality of life · Outpatients · Questionnaires · Menopause

\section{Introduction}

Electronic supplementary material The online version of this article (https://doi.org/10.1007/s10549-019-05197-whttps:// doi.org/10.1007/s10549-019-05197-w) contains supplementary material, which is available to authorized users.

Norbert Marschner

manuskript@onkologie-freiburg.de

1 Praxis für interdisziplinäre Onkologie und Hämatologie, Wirthstrasse 11c, 79110 Freiburg, Germany

2 MVZ des Klinikums Wilhelmshaven, Zentrum für Tumorbiologie, Wilhelmshaven, Germany

3 GIM Gemeinschaftspraxis Innere Medizin, Witten, Germany
Breast cancer remains the most frequent cancer among women, with approximately 266,000 estimated new cases in the US and 72,000 in Germany in 2018 [1,2]. With a 5 -year survival rate of almost $90 \%$, there is a growing number of breast cancer survivors in need of optimal care $[1,2]$.

OSP Göttingen, Göttingen, Germany

5 Hämatologisch-Onkologischer Schwerpunkt Schnelsen, Hamburg, Germany

6 Department of Biostatistics, iOMEDICO, Freiburg, Germany

7 Medical Department, iOMEDICO, Freiburg, Germany

8 Clinical Epidemiology and Health Economics, iOMEDICO, Freiburg, Germany 
In 2015, their number reached more than 3.4 million in the United States alone [2]. In patients with early breast cancer, standard of care is the surgical removal of the tumour, preceded or followed by chemotherapy, and/or preceded by radiation therapy depending on the individual risk profile of the patient. The majority (approximately $75 \%$ ) of breast cancer cases are hormone receptor-positive (HR-positive) tumours [3] for whom additional adjuvant endocrine treatment is recommended.

The choice of the specific endocrine treatment depends on the menopausal status of the patient. Premenopausal patients should receive adjuvant tamoxifen and optionally ovarian suppression, while postmenopausal patients should receive an aromatase inhibitor (anastrozole, letrozole, exemestane) or tamoxifen followed by an aromatase inhibitor [reviewed in 4]. Treatment with either tamoxifen or aromatase inhibitors should last for at least 5 years, thus the patients have to deal with a long period of medical interventions, potential side effects and the associated psychological strain, all of which can strongly affect the quality of life (QoL) [5-7].

Although recent findings suggest that endocrine therapy alone is adequate for women with low-risk tumours [8,9], additional adjuvant chemotherapy is widely used. Both systemic treatment options are associated with side effects and toxicities: while endocrine therapy may cause osteopenia, osteoporosis, arthralgia, musculoskeletal symptoms and menopausal complaints [10-14]; chemotherapy is associated with nausea, hair loss, paraesthesia, neuropathy and cardiotoxicity, some of which are persistent even years after treatment [15-17]. Furthermore, crucial side effects for premenopausal patients are treatment-induced amenorrhea or infertility [18-21]. Indeed, it has been published that younger women report greater changes for the worse regarding mood and emotional functioning in comparison to older women [22, 23].

Of note, QoL is not only impaired by side effects, but also by other factors like lack of social support or expenditure of time for treatment. These factors are especially troubling for young patients, mostly focused on career and/or caring for young children. Balancing the efficacy of systemic treatments with upholding QoL for the patient is one of the biggest challenges for oncologists. Broad and detailed evaluations of patient-reported outcomes (PROs) are necessary in order to highlight all short- and long-term effects of treatment, especially because of the growing number of breast cancer patients treated with curative intent.

The clinical cohort study TMK (Tumour Registry Breast Cancer) set out to examine the treatment of early and metastatic breast cancer in German routine care as well as the impact of the disease on various aspects of life. For patients with early breast cancer, we previously published data on the routine treatment with adjuvant chemotherapy [24] and results from the MaTox project on toxicity-related symptoms after adjuvant chemotherapy [15]. In the analysis at hand, we present data from the longitudinal MaLife project-a comprehensive assessment of PROs in a real-world setting, aiming to get a detailed understanding of the situation of patients with breast cancer in German routine care. We looked at patients of all breast cancer subtypes with documented pre- or postmenopausal status and compared the temporal change in QoL during systemic treatment and over the following 3 years.

\section{Patients and methods}

\section{Data source}

The TMK is an ongoing, open, longitudinal, multicentre, observational, prospective cohort study which started in 2007. The study was approved by the responsible ethics committee and is registered at ClinicalTrials.gov (NCT01351584). Eligible patients are women aged $\geq 18$ years with histologically confirmed breast cancer and starting systemic antineoplastic treatment. Written informed consent is obtained from all patients. Enrolment is restricted to patients who sign informed consent no longer than 6 weeks after start of treatment. The TMK has previously been described in detail [25].

The MaLife project is an ongoing, prospective, longitudinal survey within the TMK that recruited patients with early and advanced breast cancer between 2011 and 2015 to evaluate PROs during and after systemic treatment.

\section{Cohort definition}

Until data cut at 31, October 2017, a total of 2013 patients had been recruited for the MaLife project. Out of these, 1014 patients were recruited in neoadjuvant or adjuvant treatment intention. Of these, 137 patients were excluded as they had not sent back a single questionnaire or had incomplete basic medical data. 61 patients were excluded because they were classified as 'perimenopausal' at inclusion and 87 patients were excluded due to unknown menopausal status. The present analysis focused on 729 patients receiving neoadjuvant or adjuvant therapy, 251 with premenopausal, and 478 with postmenopausal status at start of therapy. The patients were recruited by 98 sites of office- and hospital-based medical oncologists and gynaecologists located all over Germany.

\section{Questionnaires}

The specifically compiled MaLife questionnaire encompasses 130 items combining both validated instruments as well as additional, specifically designed questions to assess QoL, symptoms associated with breast cancer and its 
treatment, type and time of health-care resources used, ability to work and other aspects of everyday life impairment. Feasibility of the MaLife questionnaire was tested before the start of the study. The questionnaire was sent to patients by post at start of systemic treatment as well as 6 and 12 months later and then annually up to 5 years. Reminders were sent by post 2 weeks after mailing of the questionnaires and a second reminder another 2 weeks later, if the questionnaire had not yet been returned.

In this interim analysis, we included the results from six validated questionnaires within the MaLife questionnaire: FACT-G for general quality of life [26], the FACTTaxane subscale for neurotoxicity symptoms, the endocrine symptoms subscale ESS-18 of the FACT-ES [27] and the EORTC QLQ-BR23 for breast cancer-specific symptoms [28]. Additionally, we analysed the results from the Brief Fatigue Inventory, BFI [29] and the Hospital Anxiety and Depression Scale, HADS [30].

\section{Statistical analysis}

Scoring of the questionnaires was performed according to the respective manuals. Mean change to baseline was calculated as the difference between the scores 3 years after start of treatment and the scores at baseline. Clinical meaningful differences for the respective scales were derived from previously established meaningful differences: $\geq 4$ points for the FACT-G total score, $\geq 2$ points for the FACT-G subscales [31] and 10 points (10\% of the instrument range) for the EORTC QLQ BR-23 [32, 33]. For the other scales without previously established meaningful differences, we considered a change equal to or greater than $1 / 2$ of the standard deviation (SD) at T0 clinically meaningful. This method was previously applied for the BFI and the respective subscales [34] and has been published to be a valid threshold of discrimination for changes in various QoL instruments [35, 36]. For the Taxane subscale of the FACT-Taxane, a change of $\geq 3$ points (SD at T0: 5.59 ) was considered clinically meaningful for the premenopausal patients, and a change of $\geq 4$ points (SD at T0: 7.82) for the postmenopausal patients. Accordingly, a change of $\geq 4$ points was considered clinically meaningful for the endocrine symptom subscale of the FACT-ES; a change of $\geq 1.2$ points for the BFI total score; a change of $\geq 1.3$ points on the Fatigue interference score for the premenopausal and a change of $\geq 1.2$ points for the postmenopausal patients and a change of $\geq 1.2$ points on the Fatigue intensity score. For the HADS, the developers defined three ranges for each subscale and these were implemented to identify the percentage of patients exceeding the cut-off scores: 0-7 (non-cases), 8-10 (doubtful cases) and 11-21 (definite cases) of anxiety/depression [30]. If patients experienced a recurrence of breast cancer during the observation period, the respective questionnaires after such a diagnosis were excluded from the present analysis. All analyses were performed using Dell, Inc. (2016), Dell Statistica (Software-System für Datenanalyse), version 13. software.dell.com.

\section{Results}

\section{Patient, tumour and treatment characteristics}

Basic demographic and clinical data of the pre- and postmenopausal patients receiving neoadjuvant or adjuvant therapy are shown in Table 1. Median age at start of systemic therapy was 45 years for premenopausal and 63 years for postmenopausal patients. 45 of the patients (18\%) were aged $50-55$ in the premenopausal group, and 71 of the patients (15\%) were aged 50-55 in the postmenopausal group. The prevalence of comorbidities was higher for postmenopausal than for premenopausal patients, especially hypertension was documented more frequently ( $40 \%$ of postmenopausal, 9\% of premenopausal patients). Regarding receptor status as well as tumour stage at diagnosis, the two subgroups were comparable.

Independent of the menopausal status, most patients underwent a breast-conserving surgery (69\%) and $82 \%$ received radiotherapy (Table 2). Slightly more postmenopausal women were enrolled at start of adjuvant treatment ( 84 vs. $71 \%$ ), while slightly more premenopausal women were enrolled at start of neoadjuvant treatment (29 vs. $16 \%$ ). $96 \%$ of the premenopausal and $90 \%$ of the postmenopausal patients initially received chemotherapy, mostly a combination therapy of anthracycline and taxane (Table 2). For $91 \%$ of the premenopausal and $82 \%$ of the postmenopausal patients with HER2-positive tumours, an additional anti-HER2 therapy with trastuzumab was documented. The same proportion of premenopausal and postmenopausal patients with HR-positive tumours received endocrine therapy (83-84\%). 66\% premenopausal patients received an oestrogen-receptor antagonists (mostly tamoxifen) compared to $25 \%$ postmenopausal patients (Table 2 ). $42 \%$ of the postmenopausal patients received aromatase inhibitors. A switch of endocrine agent was documented in $11 \%$ of the premenopausal and $16 \%$ of the postmenopausal patients.

\section{Questionnaire return rate}

Return rates for the questionnaire at start of systemic treatment (T0) as well as at all other time points are depicted in Fig. 1a. At later time points, return rates were slightly higher for postmenopausal patients. During the observation period, $16(6.4 \%)$ premenopausal and $49(10.3 \%)$ postmenopausal patients experienced a recurrence; 1 premenopausal patient $(0.4 \%)$ and 7 postmenopausal patients $(1.5 \%)$ died. 
Table 1 Patient and tumour characteristics

\begin{tabular}{|c|c|c|c|c|}
\hline \multirow[t]{2}{*}{ Characteristic } & \multicolumn{2}{|c|}{ Premenopausal $(n=251)$} & \multicolumn{2}{|c|}{ Postmenopausal $(n=478)$} \\
\hline & Years & Min-max & Years & Min-max \\
\hline \multirow[t]{2}{*}{ Median age at start of systemic therapy } & 45.1 & $23.4-69.4$ & 62.8 & $37.6-84.0$ \\
\hline & Mean & SD & Mean & SD \\
\hline BMI at enrolment, $\mathrm{kg} / \mathrm{m}^{2}$ & 25.5 & 5.04 & 27.5 & 5.57 \\
\hline Patients with comorbidity at diagnosis & $n$ & $\%$ & $n$ & $\%$ \\
\hline Any comorbidity ${ }^{\mathrm{a}}$ & 95 & 37.8 & 335 & 70.1 \\
\hline $\mathrm{CCI}=0^{\mathrm{b}}$ & 232 & 92.4 & 412 & 86.2 \\
\hline $\mathrm{CCI} \geq 1^{\mathrm{b}}$ & 19 & 7.6 & 66 & 13.8 \\
\hline Hypertension & 23 & 9.2 & 193 & 40.4 \\
\hline Diabetes & 1 & 0.4 & 50 & 10.5 \\
\hline Cardiovascular disorders & 5 & 2.0 & 25 & 5.2 \\
\hline \multicolumn{5}{|l|}{ Receptor status at diagnosis } \\
\hline HR-positive, HER2-negative & 158 & 62.9 & 279 & 58.4 \\
\hline HR-positive, HER2-positive & 41 & 16.3 & 72 & 15.1 \\
\hline HR-negative, HER2-positive & 12 & 4.8 & 37 & 7.7 \\
\hline Triple negative & 38 & 15.1 & 80 & 16.7 \\
\hline Unknown* & 2 & 0.8 & 10 & 2.1 \\
\hline \multicolumn{5}{|l|}{ Tumour stage at diagnosis ${ }^{c}$} \\
\hline I & 60 & 23.9 & 134 & 28.0 \\
\hline II & 119 & 47.4 & 218 & 45.6 \\
\hline III & 39 & 15.5 & 77 & 16.1 \\
\hline Not determined/Unknown ${ }^{\mathrm{d}}$ & 33 & 13.2 & 49 & 10.2 \\
\hline \multicolumn{5}{|l|}{ Nodal stage at diagnosis } \\
\hline Positive & 120 & 47.8 & 209 & 43.7 \\
\hline Negative (N0) & 121 & 48.2 & 260 & 54.4 \\
\hline Unknown (NX + missing) & 10 & 4.0 & 9 & 1.9 \\
\hline
\end{tabular}

$B M I$ Body Mass Index, $H R$ hormone receptor, $H E R 2$ human epidermal growth factor receptor 2, Max maximum, Min minimum, $S D$ standard deviation

*This category includes three patients with HR-positive tumours and unknown HER2-status

${ }^{a}$ Comorbidity according to Charlson [48] or additional concomitant diseases

${ }^{\mathrm{b}}$ Charlson Comorbidity Index (CCI) according to Quan [49]

${ }^{\mathrm{c}}$ Tumour stage according to AJCC/UICC 7th edition

${ }^{\mathrm{d}}$ For some patients the exact stage could not be determined because of unknown parameters (TX, NX, MX)

Looking at the treatment at the respective questionnaire time points, $95 \%$ (87\%) of the premenopausal (postmenopausal) patients started systemic chemotherapy and/or anti-HER2-therapy at T0 and this number declined to $12 \%$ (17\%) 6 months and 7\% (7\%) 12 months later (Fig. 1b). Overall, approximately $60 \%$ of all patients (both HR-positive and -negative) received endocrine therapy at 12, 24 and 36 months, respectively.

\section{QoL and symptom severity at start of treatment}

Baseline mean values at start of treatment (T0) for FACT-subscales and HADS were similar for pre- and postmenopausal patients (Table 3 ). In premenopausal patients, values for body image and fatigue intensity were inferior at baseline, while postmenopausal patients reported inferior values for sexual functioning and enjoyment as well as upset by hair loss (Table 3).

\section{Mean change in QoL from start of treatment (TO)}

Looking at the mean change from start of treatment for the FACT-G questionnaire, there was improvement in physical and functional well-being and a decrease in social/family well-being (Fig. 2a). However, it needs to be mentioned that the mean score for social/family well-being at $\mathrm{T} 0$ was 
Table 2 Treatment characteristics

\begin{tabular}{|c|c|c|c|c|}
\hline \multirow[t]{2}{*}{ Treatment } & \multicolumn{2}{|c|}{ Premenopausal $(n=251)$} & \multicolumn{2}{|c|}{ Postmenopausal $(n=478)$} \\
\hline & $n$ & $\%$ & $n$ & $\%$ \\
\hline \multicolumn{5}{|l|}{ Resection of primary tumour } \\
\hline Breast-conserving (incl. follow-up resection) & 173 & 68.9 & 332 & 69.5 \\
\hline Non-breast conserving (mastectomy/ablatio mammae) & 56 & 22.3 & 114 & 23.8 \\
\hline Unknown & 22 & 8.8 & 32 & 6.7 \\
\hline \multicolumn{5}{|l|}{ Radiotherapy } \\
\hline Yes & 205 & 81.7 & 392 & 82.0 \\
\hline No & 46 & 18.3 & 86 & 18.0 \\
\hline \multicolumn{5}{|l|}{ Therapy setting at enrolment } \\
\hline Neoadjuvant & 72 & 28.7 & 79 & 16.5 \\
\hline Adjuvant & 179 & 71.3 & 399 & 83.5 \\
\hline \multicolumn{5}{|l|}{ Chemotherapy } \\
\hline Yes & 242 & 96.4 & 432 & 90.4 \\
\hline No & 9 & 3.6 & 46 & 9.6 \\
\hline \multicolumn{5}{|l|}{ Chemotherapy regimen } \\
\hline $\mathrm{E} / \mathrm{A}+\mathrm{C}+\mathrm{P}$ & 70 & 27.9 & 105 & 22.0 \\
\hline $\mathrm{E} / \mathrm{A}+\mathrm{C}+\mathrm{D}$ & 46 & 18.3 & 67 & 14.0 \\
\hline $\mathrm{F}+\mathrm{E} / \mathrm{A}+\mathrm{C}+\mathrm{D}$ & 40 & 15.9 & 66 & 13.8 \\
\hline $\mathrm{F}+\mathrm{E} / \mathrm{A}+\mathrm{C}$ & 22 & 8.8 & 46 & 9.6 \\
\hline Others & 64 & 25.5 & 148 & 31.0 \\
\hline \multirow[t]{2}{*}{ Treatment } & \multicolumn{2}{|c|}{ Premenopausal, HR-positive $(n=199)$} & \multicolumn{2}{|c|}{$\begin{array}{l}\text { Postmenopausal, HR-positive } \\
(n=354)\end{array}$} \\
\hline & $n$ & $\%$ & $n$ & $\%$ \\
\hline \multicolumn{5}{|l|}{ Endocrine therapy } \\
\hline Yes & 166 & 83.4 & 296 & 83.6 \\
\hline No & 33 & 16.6 & 58 & 16.4 \\
\hline \multicolumn{5}{|l|}{ Endocrine therapy regimen } \\
\hline Aromatase inhibitors $(\mathrm{AI}) \pm \mathrm{GnRH}$ & 12 & 6.0 & 149 & 42.1 \\
\hline Oestrogen-receptor antagonist & 132 & 66.3 & 88 & 24.9 \\
\hline Switch ER-antagonist/AI & 22 & 11.1 & 55 & 15.5 \\
\hline Others & - & - & 4 & 1.1 \\
\hline
\end{tabular}

$A I$ aromatase inhibitor, $C$ cyclophosphamide, $D$ docetaxel, E/A epirubicin/doxorubicin, ER-antagonist oestrogen-receptor antagonist, $F$ fluorouracil, $G n R H$ gonadotropin-releasing hormone, $P$ paclitaxel

rather high. The mean change for the FACT-G total score showed an increased global QoL from start of treatment until 3 years later (Fig. 2b). The FACT-Taxane subscale, however, showed a persistent increase in neurotoxicity symptoms (Fig. 2c). The mean change for the endocrine symptom subscale showed an increase in symptoms, markedly more so for premenopausal patients (Fig. 2d). The mean change of the EORTC QLQ-BR23 functional scales (Fig. 2e) and symptom scales (Fig. 2f) showed no differences according to the menopausal status of the patients. The future perspective increased while the side effects of systemic treatment decreased. While the mean change in the fatigue scores showed a slight decline for the postmenopausal patients, the premenopausal patients seemed to recover from an initial slight decrease (Fig. 2g). While the mean change in the HADS depression subscale showed a decrease in depression over time, the mean change in the anxiety subscale revealed a lingering increase in anxiety in premenopausal patients (Fig. 2h).

\section{Clinical meaningful change in QoL}

The proportion of patients with clinically meaningful changes in the different QoL domains from start of treatment to 3 years later is shown in Fig. 3. The definition of the respective minimal important difference is described in the "Statistical Analysis" section. The global QoL as assessed with the FACT-G improved considerably for 


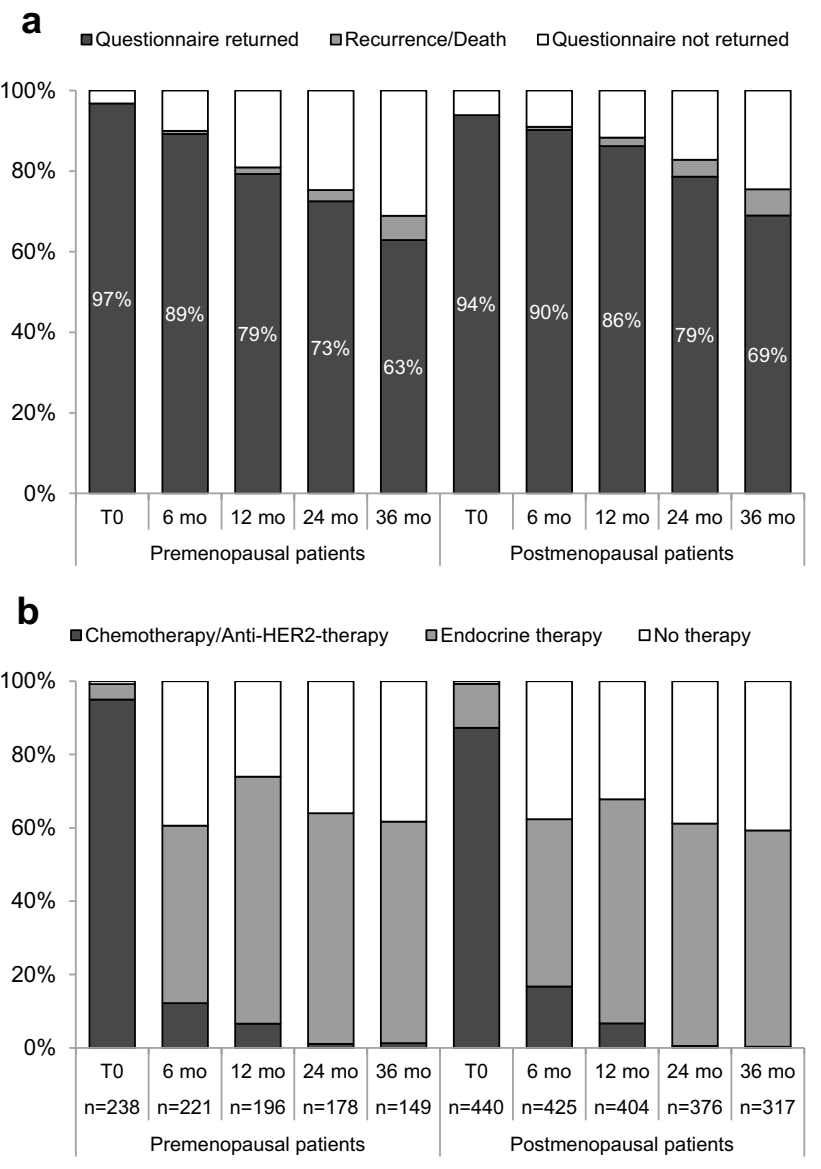

Fig. 1 Questionnaire return rate and treatment. a Return rate of the MaLife questionnaire for the premenopausal and postmenopausal patients at start of therapy (T0), 6 months, 12 months, 24 months and 36 months later. b Proportion of patients receiving systemic chemotherapy and/or anti-HER2-therapy, endocrine therapy or no therapy at the respective questionnaire time points. mo months

approximately half of the patients (Fig. 3a). 36\% of the premenopausal and $37 \%$ of the postmenopausal patients reported a meaningful increase in emotional well-being; in contrast, $36 \%$ of the premenopausal and $24 \%$ of the postmenopausal patients reported a meaningful decrease. The scales with the worst deterioration 3 years after start of treatment were social/family well-being, the taxane subscale and the endocrine symptom subscale. Roughly half of the patients reported a significantly worse social/family well-being, regardless of the menopausal status. Neurotoxicity symptoms as assessed with the taxane subscale, worsened considerably for $55-56 \%$ of the patients. $64 \%$ of the premenopausal patients ( $48 \%$ of the postmenopausal patients) reported a clinically meaningful worsening of endocrine symptoms. Regarding the side effects of systemic treatment, $55 \%$ of the premenopausal $(47 \%$ of the postmenopausal) patients reported clinically meaningful improvement. $44-49 \%$ of the patients reported an increase in arm symptoms and $27 \%$ of the premenopausal and $17 \%$ of the postmenopausal patients reported a decrease in body image. $37 \%$ of the premenopausal (24\% of the postmenopausal) patients reported a worsening in fatigue intensity 3 years after start of treatment.

Looking at anxiety and depression as assessed with the HADS (Fig. 3b), there was an increase in the proportion of premenopausal patients with anxiety (14\% doubtful and $12 \%$ definite cases at T0 vs. $15 \%$ doubtful and $18 \%$ definite cases 3 years later) and no change in the proportion of premenopausal patients with depression (Fig. 3b). Contrarily, the proportion of postmenopausal patients with anxiety decreased slightly and the proportion with depression decreased considerably (18\% doubtful and $13 \%$ definite cases at T0 vs. $11 \%$ doubtful and $10 \%$ definite cases 3 years later).

Because most chemotherapies are finished 6 months after start of treatment (T1), we took a closer look at the clinical meaningful change from this time point until 3 years later. The mean values at $\mathrm{T} 1$ are shown in Table $\mathrm{S} 1$, and the percentages of patients with clinically meaningful changes in QoL in this period are presented in Figure S1. The results show that $59 \%$ premenopausal and $55 \%$ postmenopausal patients report a significant improvement in functional well-being from end of chemotherapy until 3 years later. Likewise, $55 \%$ premenopausal and $45 \%$ postmenopausal patients report a meaningful improvement in physical wellbeing in this period (Figure S1). Looking at social/family well-being, 25\% premenopausal and 19\% postmenopausal patients reported a significant improvement while $42 \%$ premenopausal and 39\% postmenopausal reported a significant deterioration. A total of $49 \%$ premenopausal and $38 \%$ postmenopausal patients reported a meaningful improvement in neurotoxicity (Taxane subscale), while $18 \%$ premenopausal and $27 \%$ postmenopausal patients reported a meaningful deterioration. However, the mean FACT-Taxane scores at T1 were inferior to the mean scores at T0 (premenopausal 49.7 vs. 59.8; postmenopausal 47.9 vs. 60.2 , Table 3 and S1). Similar tendencies were reported for the endocrine symptom subscale: $33 \%$ premenopausal and $22 \%$ postmenopausal patients reported a significant improvement, $30 \%$ premenopausal and $32 \%$ postmenopausal patients a significant deterioration after end of chemotherapy. These initial deteriorations and subsequent slight improvement/stabilisation are also visible in the mean change graph (Fig. 2).

Of note, patients reporting poor QoL at $\mathrm{T} 1$ and no improvement 3 years later appear in the "no change" category, just like the patients reporting good QoL at both time points. 
Table 3 QoL and symptom severity at start of treatment (T0)

\begin{tabular}{|c|c|c|c|c|c|}
\hline \multirow[t]{2}{*}{ Scale } & \multirow[t]{2}{*}{ Range } & \multicolumn{2}{|c|}{ Premenopausal $(n=251)$} & \multicolumn{2}{|c|}{$\begin{array}{l}\text { Postmenopausal } \\
(n=478)\end{array}$} \\
\hline & & $n$ & Mean \pm SD & $n$ & Mean \pm SD \\
\hline \multicolumn{6}{|l|}{ FACT-G ${ }^{\mathrm{a}}$} \\
\hline FACT-G global score & $0-108$ & 233 & $75.5 \pm 15.40$ & 426 & $75.8 \pm 15.89$ \\
\hline Physical well-being & $0-28$ & 236 & $18.4 \pm 6.28$ & 436 & $18.9 \pm 6.40$ \\
\hline Social/family well-being & $0-28$ & 235 & $23.1 \pm 4.68$ & 429 & $22.9 \pm 4.81$ \\
\hline Emotional well-being & $0-24$ & 237 & $17.9 \pm 4.09$ & 436 & $17.9 \pm 4.45$ \\
\hline Functional well-being & $0-28$ & 237 & $15.9 \pm 5.89$ & 436 & $15.9 \pm 5.87$ \\
\hline \multicolumn{6}{|l|}{ FACT-Taxane $^{a}$} \\
\hline FACT-Taxane subscale & $0-64$ & 231 & $58.7 \pm 5.59$ & 434 & $57.0 \pm 7.82$ \\
\hline \multicolumn{6}{|l|}{ FACT-ES $^{\mathrm{a}}$} \\
\hline Endocrine Symptom Subscale-18 & $0-72$ & 235 & $59.8 \pm 7.45$ & 436 & $60.2 \pm 8.15$ \\
\hline \multicolumn{6}{|l|}{ EORTC QLQ-BR23 $^{\mathrm{a}}$} \\
\hline Body image & $0-100$ & 235 & $64.3 \pm 30.40$ & 436 & $70.0 \pm 30.05$ \\
\hline Future perspective & $0-100$ & 232 & $47.0 \pm 31.33$ & 434 & $44.5 \pm 31.75$ \\
\hline Sexual functioning & $0-100$ & 226 & $29.9 \pm 28.92$ & 377 & $17.8 \pm 25.06$ \\
\hline Sexual enjoyment* & $0-100$ & 110 & $77.6 \pm 25.98$ & 99 & $63.3 \pm 24.51$ \\
\hline \multicolumn{6}{|l|}{ EORTC QLQ-BR23 $^{\mathrm{b}}$} \\
\hline Systemic therapy side effects & $0-100$ & 236 & $41.7 \pm 21.47$ & 437 & $39.9 \pm 21.34$ \\
\hline Breast symptoms & $0-100$ & 235 & $24.0 \pm 22.86$ & 434 & $22.1 \pm 20.84$ \\
\hline Arm symptoms & $0-100$ & 235 & $22.3 \pm 22.44$ & 435 & $21.5 \pm 22.19$ \\
\hline Upset by hair loss & $0-100$ & 225 & $39.3 \pm 40.51$ & 423 & $44.6 \pm 43.38$ \\
\hline \multicolumn{6}{|l|}{ Brief fatigue inventory ${ }^{b}$} \\
\hline BFI total score & $0-10$ & 225 & $3.2 \pm 2.32$ & 416 & $3.0 \pm 2.31$ \\
\hline Fatigue intensity & $0-10$ & 224 & $4.2 \pm 2.37$ & 402 & $3.6 \pm 2.37$ \\
\hline Fatigue interference & $0-10$ & 225 & $2.8 \pm 2.52$ & 417 & $2.7 \pm 2.41$ \\
\hline \multicolumn{6}{|l|}{ HADS $^{b}$} \\
\hline HADS total score & $0-42$ & 229 & $11.2 \pm 6.69$ & 419 & $11.5 \pm 6.95$ \\
\hline Anxiety & $0-21$ & 232 & $5.8 \pm 3.34$ & 424 & $5.9 \pm 3.57$ \\
\hline Depression & $0-21$ & 231 & $5.3 \pm 3.97$ & 423 & $5.6 \pm 3.93$ \\
\hline
\end{tabular}

FACT-G global score: $\mathrm{PWB}+\mathrm{SWB}+\mathrm{EWB}+\mathrm{FWB}$

$B F I$ Brief Fatigue Inventory, HADS hospital anxiety and depression scale, $S D$ standard deviation

*If sexually active

${ }^{a}$ High scores indicate high quality of life/low symptom severity

${ }^{\mathrm{b}}$ High scores indicate high symptom severity

\section{Discussion}

This first interim analysis of the MaLife project aims at a comprehensive assessment of the QoL of patients with early breast cancer from start of treatment until 3 years later, with a special focus on the menopausal status. Regardless of the menopausal status, a high percentage of patients reported substantial improvements in global quality of life, especially in functional and physical well-being as well as for side effects of systemic treatment and depression. However, approximately half of all patients reported a distinct decrease in social/family well-being and a worsening of arm symptoms, endocrine symptoms and neurotoxicity symptoms. The presented data may help the treating physicians to discuss the situation with their patient-by looking at the clinically meaningful changed QoL scores both at start of treatment and after end of chemotherapy. Our data show that pre- and postmenopausal patients have differing needs in follow-up care. A higher percentage of premenopausal patients report worsening in body image, endocrine symptoms, fatigue intensity and anxiety 3 years after start of treatment. Especially for these young patients, mostly focused on career and caring for young children, improvement in treatment and follow-up care is urgently needed.

As expected, not all initially participating patients sent back the subsequent questionnaires, representing one potential limitation of this project. However, the return rate of the questionnaires was exceptionally high, strengthening the 

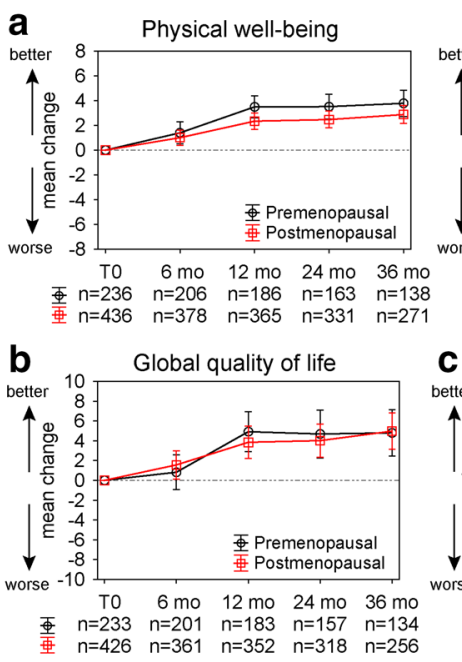
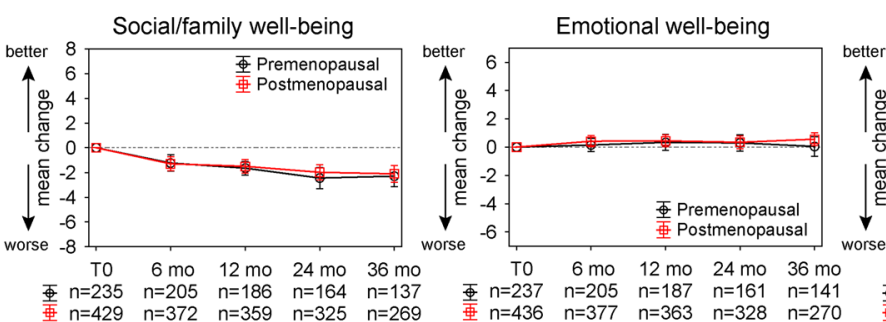

$\begin{array}{ccccc}\text { TO } & 6 \text { mo } & 12 \text { mo } & 24 \text { mo } & 36 \text { mo } \\ \text { 熏 } n=237 & n=205 & n=187 & n=161 & n=141 \\ \text { 要 } n=436 & n=377 & n=363 & n=328 & n=270\end{array}$

d Endocrine symptoms

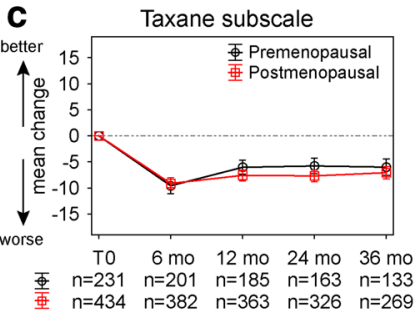

$n=429 \quad n=372 \quad n=359 \quad n=325 \quad n \quad n$

C

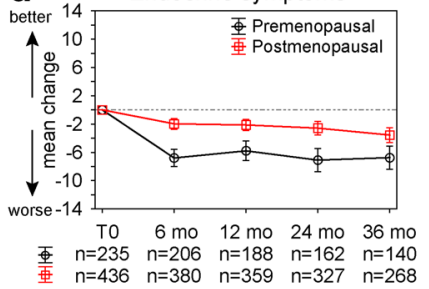

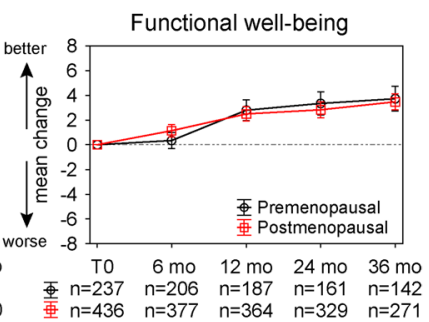

重 $n=237 \quad n=206 \quad n=187 \quad n=161 \quad n=142$
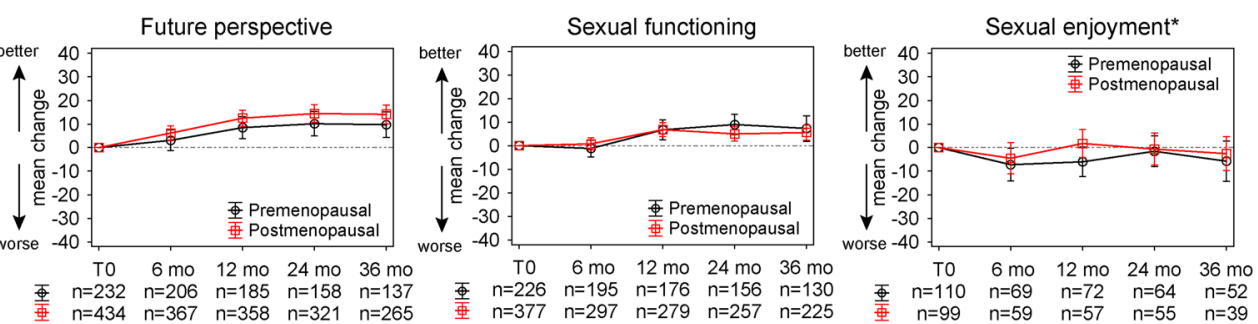

f

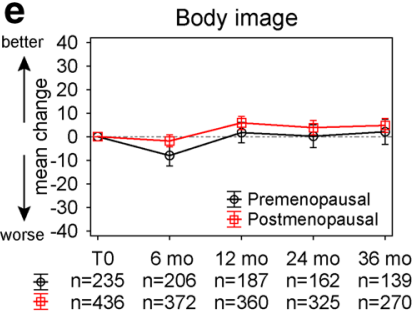

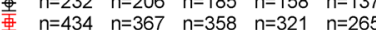

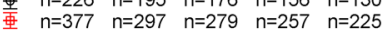

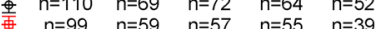
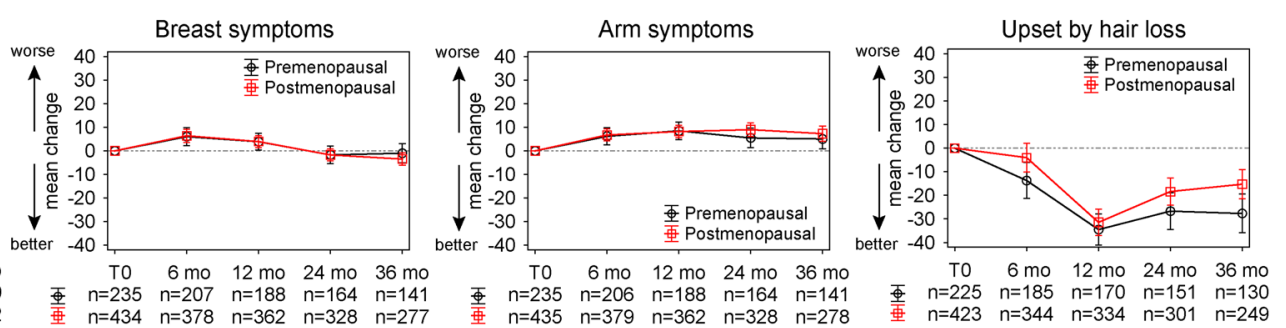

年 $n=236 \quad n=207 \quad n=186 \quad n=162 \quad n=139$

$n=235 \quad n=207 \quad n=188 \quad n=164 \quad n=141$

垂 $n=435 \quad n=379 \quad n=362 \quad n=328 \quad n=278$

$n=423 \quad n=344 \quad n=334 \quad n=301 \quad n=249$

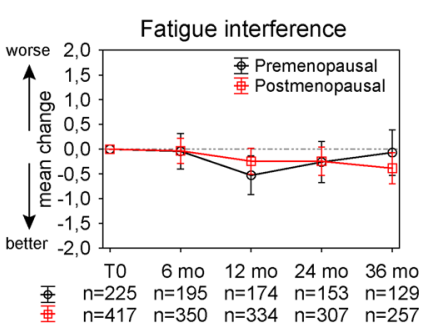

$\begin{array}{llll}6 \mathrm{mo} & 12 \mathrm{mo} & 24 \mathrm{mo} & 36 \mathrm{mo}\end{array}$ $\begin{array}{lllll}n=225 & n=195 & n=174 & n=153 & n=129 \\ n=416 & n=349 & n=333 & n=306 & n=256\end{array}$

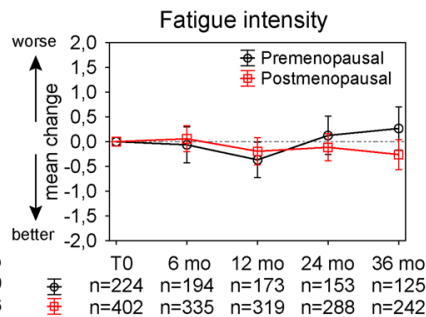

h

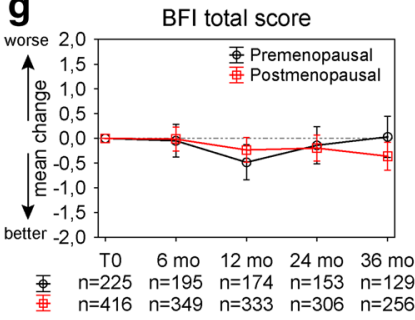

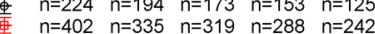
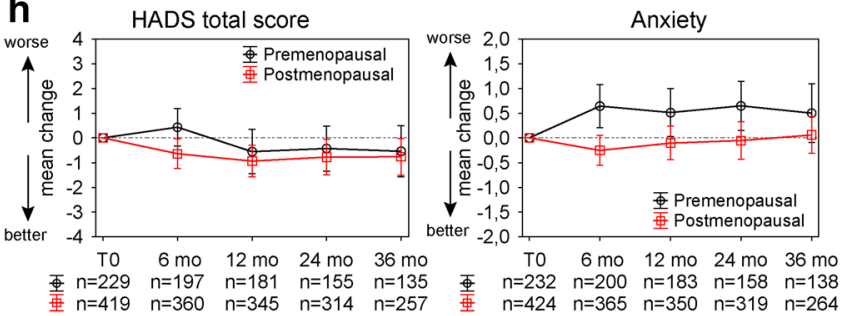

Fig. 2 Mean change in quality of life over 3 years. Shown is the mean change from start of therapy (T0) until 6, 12, 24 and 36 months later. Error bars represent the $95 \%$ confidence interval at each time point. Higher values indicate an improved quality of life in a FACT-G subscales and b FACT-G total score, $\mathbf{c}$ FACT-Taxane subscale, d FACTES endocrine symptoms subscale and e EORTC QLQ-BR23 func-

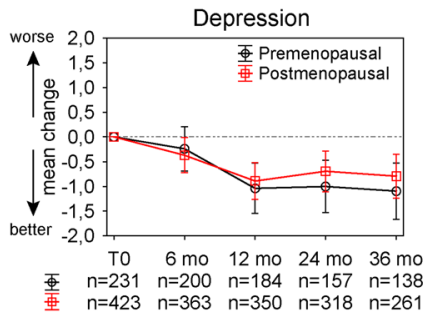

tional scales. Higher values indicate a worsening of symptom severity in $\mathbf{f}$ EORTC QLQ-BR23 symptom scales, $\mathbf{g}$ BFI total score and subscales and $\mathbf{h}$ HADS total score and subscales. *If sexually active. $B F I$ Brief Fatigue Index, HADS Hospital Anxiety and Depression Scale, mo months, syst systemic 
a Percentage of patients with clinically meaningful change* in QoL 3 years after start of treatment

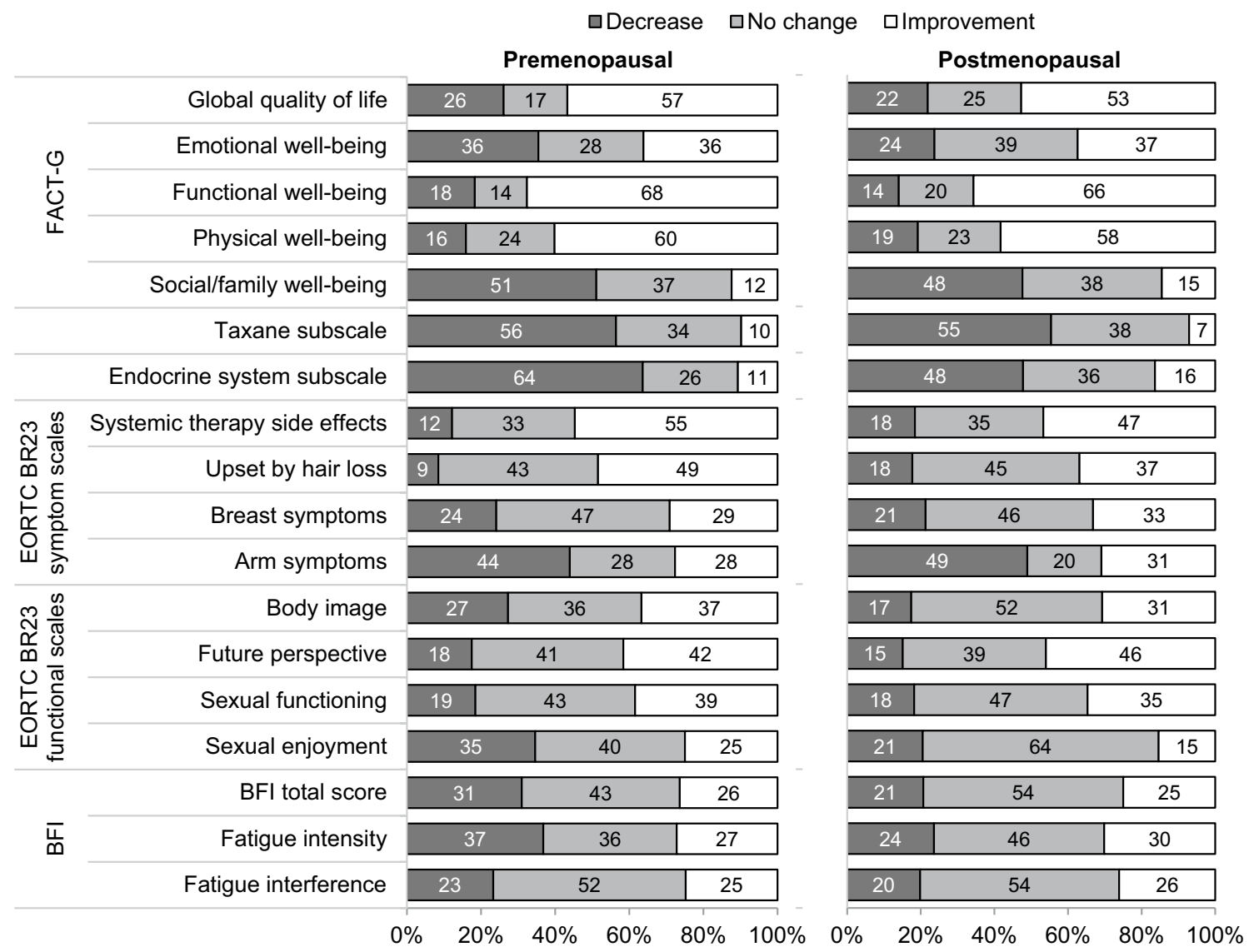

\section{b Percentage of patients with values within the HADS cut-off scores}

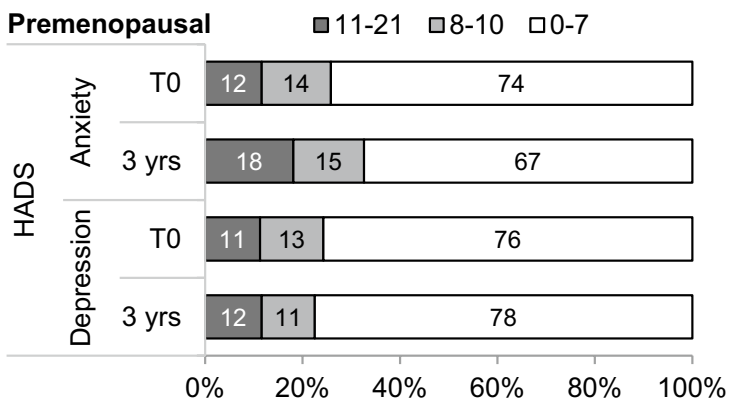

Fig. 3 Clinically meaningful changes in QoL 3 years after start of treatment. a Percentage of patients with clinically meaningful change in each QoL score 3 years after start of treatment in comparison to the values at T0. All patients who returned the questionnaires at start of treatment and 3 years later were included in this analysis, the respective $n$ corresponds to the number of patients indicated at the 36 months of time point in Fig. 2. *Minimal important difference: 10 points for EORTC QLQ-BR23 scales, 4 points for FACT-G

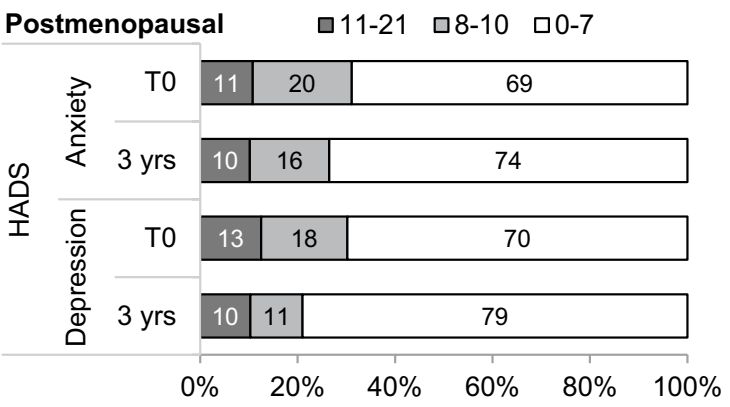

total scale, 2 points for FACT-G subscales, $1 / 2$ of the baseline standard deviation for the Taxane subscale ( 3 points for pre- and 4 points for postmenopausal patients), for the Endocrine symptoms subscale (4 points), the BFI total score (1.2 points), the Fatigue intensity scale (1.2 points) and the Fatigue interference scale (1.3 points for the pre- and 1.2 points for the postmenopausal patients). b Percentage of patients within the HADS categories at start of treatment (T0) and 3 years later. $y r s$ years 
generalisability of our data. Due to the high proportion of patients receiving chemotherapy, the results from our cohort may not be generalised to patients receiving endocrine therapy, because the symptoms might differ. Strengths of this project are the prospective, longitudinal data collection and the participation of oncologists from all over Germany recruiting a large, representative study cohort.

QoL plays an important role in recovery-especially after an incisive diagnosis such as breast cancer. QoL assessments have been shown to improve the communication between physician and patient and encourage shared decision making [reviewed in 6]. The pre- and postmenopausal patients with early breast cancer in the MaLife cohort displayed a comparable distribution of receptor status and tumour stage. Additionally, approximately the same proportion of pre- and postmenopausal patients received radiotherapy and breastconserving surgery. Both pre- and postmenopausal women reported an increase in global QoL over time, in contrast to previous reports stating that older patients adjust more easily to their breast cancer diagnosis than younger women $[22,37,38]$.

Comparing our data on the mean FACT-G global score 3 years after start of systemic therapy (81.6 for pre- and 81.1 for postmenopausal patients) with reference data for the general population, American women reported a similar QoL (80.1), while Austrian women reported a slightly better global QoL (85.5) than the MaLife cohort [31, 39, 40]. Regardless of the menopausal status, the social/family well-being decreased steadily - approximately half of the patients reported a clinical meaningful worsening 3 years after start of treatment. Of note, the mean scores at baseline for pre- and postmenopausal patients (23.1 and 22.9) were higher than the scores reported by women of the general population (20.4, Austria and 19.1, United States) or women with breast cancer (18.3, Austria) [31,39, 40]. Nevertheless, the constant decrease warrants improvements in follow-up care addressing social well-being.

The younger, premenopausal patients (median age 45 years) more frequently reported a clinically relevant worsening of fatigue intensity, body image and endocrine symptoms 3 years after start of treatment. Furthermore, $15 \%$ of the premenopausal patients classified as "doubtful cases" of anxiety and $18 \%$ as "definite cases" of anxiety 3 years after start of treatment. It has been published before that younger women report greater changes in body image, sexuality and mood, but also worse emotional and social functioning [22, 32, 41, 42]. This is probably due to treatment-related menopause, causing menopausal symptoms and infertility with a distinct negative impact on QoL [42, 43]. However, other aspects influencing the QoL in younger women are the circumstances-until diagnosis of breast cancer, younger women mostly pursue their career and are engaged in child-rearing activities. Treatment time, fatigue, pain and fear of relapse influence their daily life profoundly, although natural ageing processes must also be considered. Another aspect that needs to be addressed in follow-up care is neurotoxicity. The main symptom of neurotoxicity is peripheral neuropathy, associated with paraesthesia and numbness of fingers and toes, which is known to persist for years $[15,44-46]$. Indeed, $55-56 \%$ of the patients in the MaLife cohort reported a clinically meaningful worsening of taxane-related toxicity 3 years after start of treatment, confirming the persistence of symptoms. However, after end of chemotherapy until 3 years later, $49 \%$ premenopausal and $38 \%$ postmenopausal patients reported a significant improvement in neurotoxicity symptoms. Taxanes are widely used in the adjuvant setting, also in patients with HR-positive tumours, despite current guidelines recommending only endocrine treatment for HR-positive breast cancer [8,9]. There are still no recommendations for prevention and treatment of peripheral neuropathy [reviewed in 47] and research in that direction is of clinical importance.

\section{Conclusion}

Our comprehensive assessment of QoL over the course of 3 years in women with early breast cancer treated in routine care in Germany highlights the areas requiring special attention in treatment decision making and follow-up care. Even 3 years after start of treatment, approximately half of the patients report a clinically significant decrease in social/ family well-being, as well as a worsening of arm symptoms, neurotoxicity and endocrine symptoms. Younger, premenopausal patients more frequently report worsening in emotional well-being, anxiety, body image and endocrine symptoms in comparison to the values at baseline. It is of high interest for all physicians to discuss these topics with their patients and indicate those areas requiring special attention during follow-up care.

Acknowledgements The authors thank all patients, physicians and study teams participating in the TMK and the MaLife Project. We thank Emil Boller, Michaela Schnitzler and Natalie Wetzel (iOMEDICO) for support with the statistical analyses. We thank Dr. Leonora Houet (iOMEDICO) for critically reviewing the manuscript. The TMK and the MaLife project are designed, managed and analysed by iOMEDICO and have received continuous financial support from Roche Pharma AG and temporary financial support from Hexal AG and Novartis Pharma GmbH. None of the funders had any role in study design, data collection and analysis, interpretation of results, decision to publish, or preparation of the manuscript. The TMK Study Group collaborates with the Arbeitskreis Klinische Studien in onkologischen und hämatologischen Praxen e.V. and the Arbeitsgemeinschaft Internistische Onkologie in der deutschen Krebsgesellschaft e.V. 


\section{Compliance with ethical standards}

Conflict of interest TT, JR, DM, SM-H, JH, SD, LK and MJ declare no conflict of interest concerning the topic of this publication. NM has received travel expenses from Roche, Novartis, Celgene and Amgen for attendance of advisory boards.

Ethical approval All experiments comply with the current laws in Germany, where they were performed. All procedures performed in studies involving human participants were in accordance with the ethical standards of the national research committee and with the 1964 Helsinki declaration and its later amendments.

Open Access This article is distributed under the terms of the Creative Commons Attribution 4.0 International License (http://creativeco mmons.org/licenses/by/4.0/), which permits unrestricted use, distribution, and reproduction in any medium, provided you give appropriate credit to the original author(s) and the source, provide a link to the Creative Commons license, and indicate if changes were made.

\section{References}

1. Robert Koch-Institut Gesellschaft der epidemiologischen Krebsregister in Deutschland e.V (2017) Krebs in Deutschland 2013/2014. Häufigkeiten und Trends, 11. Ausgabe. Robert KochInstitut, Berlin

2. Noone A, Howlader N, Krapcho M et al (2017) SEER cancer statistics review, 1975-2015. Based on November 2017 SEER data submission, posted to the SEER web site, April 2018. National Cancer Institute, Bethesda

3. Ganz PA (2005) Breast cancer, menopause, and long-term survivorship: critical issues for the 21st century. Am J Med 118(Suppl 12B):136-141. https://doi.org/10.1016/j.amjmed.2005.09.047

4. De Vos FYFL, van Laarhoven HWM, Laven JSE et al (2012) Menopausal status and adjuvant hormonal therapy for breast cancer patients: a practical guideline. Crit Rev Oncol Hematol 84:252-260. https://doi.org/10.1016/j.critrevonc.2012.06.005

5. Montazeri A (2008) Health-related quality of life in breast cancer patients: a bibliographic review of the literature from 1974 to 2007. J Exp Clin Cancer Res CR 27:32. https://doi. org/10.1186/1756-9966-27-32

6. Perry S, Kowalski TL, Chang C-H (2007) Quality of life assessment in women with breast cancer: benefits, acceptability and utilization. Health Qual Life Outcomes 5:24. https://doi. org/10.1186/1477-7525-5-24

7. Paraskevi T (2012) Quality of life outcomes in patients with breast cancer. Oncol Rev. https://doi.org/10.4081/oncol.2012.e2

8. Gluz O, Nitz UA, Christgen M et al (2016) West German Study Group Phase III PlanB Trial: first prospective outcome data for the 21-gene recurrence score assay and concordance of prognostic markers by central and local pathology assessment. J Clin Oncol 34:2341-2349. https://doi.org/10.1200/JCO.2015.63.5383

9. Cardoso F, van't Veer LJ, Bogaerts J et al (2016) 70-gene signature as an aid to treatment decisions in early-stage breast cancer. N Engl J Med 375:717-729. https://doi.org/10.1056/NEJMoa1602 253

10. Dent SF, Gaspo R, Kissner M, Pritchard KI (2011) Aromatase inhibitor therapy: toxicities and management strategies in the treatment of postmenopausal women with hormone-sensitive early breast cancer. Breast Cancer Res Treat 126:295-310. https://doi. org/10.1007/s10549-011-1351-3
11. Amir E, Seruga B, Niraula $S$ et al (2011) Toxicity of adjuvant endocrine therapy in postmenopausal breast cancer patients: a systematic review and meta-analysis. J Natl Cancer Inst 103:1299-1309. https://doi.org/10.1093/jnci/djr242

12. Presant CA, Bosserman L, Young T et al (2007) Aromatase inhibitor-associated arthralgia and/ or bone pain: frequency and characterization in non-clinical trial patients. Clin Breast Cancer 7:775-778. https://doi.org/10.3816/CBC.2007.n.038

13. Burstein HJ, Temin S, Anderson H et al (2014) Adjuvant endocrine therapy for women with hormone receptor-positive breast cancer: American Society of Clinical Oncology clinical practice guideline focused update. J Clin Oncol 32:2255-2269. https:// doi.org/10.1200/JCO.2013.54.2258

14. Rimawi M, Osborne C (2014) Chap. 43: Adjuvant systemic therapy: endocrine therapy. In: Harris JR, Lippman ME, Morrow M, Osborne CK (eds) Diseases of the breast, 5th edn. Wolters Kluwer Health Adis (ESP), New Delhi

15. Hurtz H-J, Tesch H, Göhler T et al (2017) Persistent impairments 3 years after (neo)adjuvant chemotherapy for breast cancer: results from the MaTox project. Breast Cancer Res Treat 165:721-731. https://doi.org/10.1007/s10549-017-4365-7

16. Partridge AH, Burstein HJ, Winer EP (2001) Side effects of chemotherapy and combined chemohormonal therapy in women with early-stage breast cancer. J Natl Cancer Inst Monogr 30:135-142

17. Shapiro CL, Recht A (2001) Side effects of adjuvant treatment of breast cancer. N Engl J Med 344:1997-2008. https://doi. org/10.1056/NEJM200106283442607

18. Davis AL, Klitus M, Mintzer DM (2005) Chemotherapy-induced amenorrhea from adjuvant breast cancer treatment: the effect of the addition of taxanes. Clin Breast Cancer 6:421-424. https://doi. org/10.3816/CBC.2005.n.046

19. Pérez-Fidalgo JA, Roselló S, García-Garré E et al (2010) Incidence of chemotherapy-induced amenorrhea in hormone-sensitive breast cancer patients: the impact of addition of taxanes to anthracycline-based regimens. Breast Cancer Res Treat 120:245-251. https://doi.org/10.1007/s10549-009-0426-x

20. Bines J, Oleske DM, Cobleigh MA (1996) Ovarian function in premenopausal women treated with adjuvant chemotherapy for breast cancer. J Clin Oncol 14:1718-1729. https://doi. org/10.1200/JCO.1996.14.5.1718

21. Ganz PA, Desmond KA, Leedham B et al (2002) Quality of life in long-term, disease-free survivors of breast cancer: a follow-up study. J Natl Cancer Inst 94:39-49

22. Ganz PA, Greendale GA, Petersen L et al (2003) Breast cancer in younger women: reproductive and late health effects of treatment. J Clin Oncol 21:4184-4193. https://doi.org/10.1200/ JCO.2003.04.196

23. Ganz PA, Rowland JH, Desmond K et al (1998) Life after breast cancer: understanding women's health-related quality of life and sexual functioning. J Clin Oncol 16:501-514. https://doi. org/10.1200/JCO.1998.16.2.501

24. Dörfel S, Steffens C-C, Meyer D et al (2017) Adjuvant chemotherapeutic treatment of 1650 patients with early breast cancer in routine care in Germany: data from the prospective TMK cohort study. Breast Cancer. https://doi.org/10.1007/s12282-017-0823-7

25. Fietz T, Tesch H, Rauh J et al (2017) Palliative systemic therapy and overall survival of 1,395 patients with advanced breast cancer-results from the prospective German TMK cohort study. Breast Edinb Scotl 34:122-130. https://doi.org/10.1016/j.breas t.2017.05.014

26. Cella DF, Tulsky DS, Gray G et al (1993) The Functional Assessment of Cancer Therapy scale: development and validation of the general measure. J Clin Oncol 11:570-579

27. Fallowfield LJ, Leaity SK, Howell A et al (1999) Assessment of quality of life in women undergoing hormonal therapy for breast 
cancer: validation of an endocrine symptom subscale for the FACT-B. Breast Cancer Res Treat 55:189-199

28. Sprangers MA, Groenvold M, Arraras JI et al (1996) The European Organization for Research and Treatment of Cancer breast cancer-specific quality-of-life questionnaire module: first results from a three-country field study. J Clin Oncol 14:2756-2768

29. Mendoza TR, Wang XS, Cleeland CS et al (1999) The rapid assessment of fatigue severity in cancer patients: use of the Brief Fatigue Inventory. Cancer 85:1186-1196

30. Zigmond AS, Snaith RP (1983) The hospital anxiety and depression scale. Acta Psychiatr Scand 67:361-370

31. Pearman T, Yanez B, Peipert J et al (2014) Ambulatory cancer and US general population reference values and cutoff scores for the functional assessment of cancer therapy. Cancer 120:2902-2909. https://doi.org/10.1002/cncr.28758

32. Arndt V, Merx H, Stegmaier C et al (2005) Persistence of restrictions in quality of life from the first to the third year after diagnosis in women with breast cancer. J Clin Oncol 23:4945-4953. https://doi.org/10.1200/JCO.2005.03.475

33. Osoba D, Rodrigues G, Myles J et al (1998) Interpreting the significance of changes in health-related quality-of-life scores. J Clin Oncol 16:139-144

34. Sternberg CN, Molina A, North S et al (2013) Effect of abiraterone acetate on fatigue in patients with metastatic castrationresistant prostate cancer after docetaxel chemotherapy. Ann Oncol 24:1017-1025. https://doi.org/10.1093/annonc/mds585

35. Norman GR, Sloan JA, Wyrwich KW (2003) Interpretation of changes in health-related quality of life: the remarkable universality of half a standard deviation. Med Care 41:582-592. https://doi. org/10.1097/01.MLR.0000062554.74615.4C

36. Sloan JA, Cella D, Hays RD (2005) Clinical significance of patient-reported questionnaire data: another step toward consensus. J Clin Epidemiol 58:1217-1219. https://doi.org/10.1016/j. jclinepi.2005.07.009

37. Kroenke CH, Rosner B, Chen WY et al (2004) Functional impact of breast cancer by age at diagnosis. J Clin Oncol 22:1849-1856. https://doi.org/10.1200/JCO.2004.04.173

38. Ganz PA, Guadagnoli E, Landrum MB et al (2003) Breast cancer in older women: quality of life and psychosocial adjustment in the 15 months after diagnosis. J Clin Oncol 21:4027-4033. https:// doi.org/10.1200/JCO.2003.08.097

39. Holzner B, Kemmler G, Cella D et al (2004) Normative data for functional assessment of cancer therapy - general scale and its use for the interpretation of quality of life scores in cancer survivors. Acta Oncol 43:153-160

40. Brucker PS, Yost K, Cashy J et al (2005) General population and cancer patient norms for the Functional Assessment of Cancer
Therapy-General (FACT-G). Eval Health Prof 28:192-211. https ://doi.org/10.1177/0163278705275341

41. Befort CA, Klemp J (2011) Sequelae of Breast Cancer and the Influence of Menopausal Status at Diagnosis Among Rural Breast Cancer Survivors. J Womens Health 20:1307-1313. https://doi. org/10.1089/jwh.2010.2308

42. Howard-Anderson J, Ganz PA, Bower JE, Stanton AL (2012) Quality of life, fertility concerns, and behavioral health outcomes in younger breast cancer survivors: a systematic review. J Natl Cancer Inst 104:386-405. https://doi.org/10.1093/jnci/djr541

43. Vincent AJ (2015) Management of menopause in women with breast cancer. Climact J Int Menopause Soc 18:690-701. https:// doi.org/10.3109/13697137.2014.996749

44. Andersen KG, Jensen M-B, Kehlet H et al (2012) Persistent pain, sensory disturbances and functional impairment after adjuvant chemotherapy for breast cancer: cyclophosphamide, epirubicin and fluorouracil compared with docetaxel + epirubicin and cyclophosphamide. Acta Oncol Stockh Swed 51:1036-1044. https:// doi.org/10.3109/0284186X.2012.692884

45. Grisold W, Cavaletti G, Windebank AJ (2012) Peripheral neuropathies from chemotherapeutics and targeted agents: diagnosis, treatment, and prevention. Neuro-Oncol 14:iv45-iv54. https://doi. org/10.1093/neuonc/nos203

46. Siegel R, DeSantis C, Virgo K et al (2012) Cancer treatment and survivorship statistics, 2012. CA Cancer J Clin 62:220-241. https ://doi.org/10.3322/caac.21149

47. Hershman DL, Lacchetti C, Dworkin RH et al (2014) Prevention and management of chemotherapy-induced peripheral neuropathy in survivors of adult cancers: American Society of Clinical Oncology clinical practice guideline. J Clin Oncol 32:1941-1967. https ://doi.org/10.1200/JCO.2013.54.0914

48. Charlson ME, Pompei P, Ales KL, MacKenzie CR (1987) A new method of classifying prognostic comorbidity in longitudinal studies: development and validation. J Chronic Dis 40:373-383

49. Quan H, Li B, Couris CM et al (2011) Updating and validating the Charlson comorbidity index and score for risk adjustment in hospital discharge abstracts using data from 6 countries. Am J Epidemiol 173:676-682. https://doi.org/10.1093/aje/kwq433

Publisher's Note Springer Nature remains neutral with regard to jurisdictional claims in published maps and institutional affiliations. 